\title{
An Implementation of A Cycling Safety Education Program Among School Children Without Previous Formal Cycling Training: A Case Study in Serbia
}

Svetlana Bačkalić ( $\boldsymbol{\sim}$ basic@uns.ac.rs )

University of Novi Sad

Dragana Stanojević

University of Priština - Kosovska Mitrovica

Dragan Jovanović

University of Novi Sad

\section{Boško Matović}

University of Novi Sad

Miloš Pljakić

University of Priština - Kosovska Mitrovica

\section{Research Article}

Keywords: cycling, education, knowledge, cycling skills, school children

Posted Date: December 7th, 2020

DOI: https://doi.org/10.21203/rs.3.rs-113920/v1

License: (c) (i) This work is licensed under a Creative Commons Attribution 4.0 International License.

Read Full License 


\section{Abstract}

Background: The promotion of cycling as a healthy and socio-economically acceptable way of moving has led to a significant increase in these road users. Moreover, the indisputable fact is that children cyclists belong to the group of the vulnerable road users. All this clearly indicates that cycling education programs for children are the only correct approach. The primary goal of the presented research are inception and implementation of a cycling safety education program for school-age children without formal cycling knowledge and skills.

Methods: Students from the 4th grade ( 9 and 10 years old) from nine randomly schools on the territory of the Republic of Serbia participated in a survey. In order to measure and evaluate the knowledge and skills, the students were put through testing before and after the cycling safety education program. Data were analysed using repeated multivariate analysis of variance test.

Results: Comparing the intervention group and the control group before and after the training program implementation, children's total cycling knowledge increased in the intervention group. The cycling education program improved children's knowledge of road signs, age requirements, and risky behaviours. The results show that the cycling education program achieved significant improvements in all tested children's cycling skills. However, it was noticed that there was no significant intervention effect between control and intervention group in terms of the bicycle checking before riding.

Conclusions: The current research, as a pilot study, provides evidence that cycling education programs might be effective in improving cycling-related knowledge and cycling skills among children. Future efforts should be directed towards promotion and implementation of cycling safety education programs in elementary schools where there is no formal cycling training for children on traffic safety, as well as towards monitoring of long-term effects of cycling training.

\section{Background}

In recent years, there has been an obvious tendency to promote cycling as a way to improve health, socioeconomic and traffic conditions within a community. There are multiple advantages of cycling, such as improvement of physical development [1] and mental health in children [2-4]. Furthermore, there are significant advantages in environment protection as well (cleaner air, less noise, fewer traffic jams), it is cheaper than all other means of transportation, and all that means higher quality of life for everyone $[5,6]$. Cycling also affects development of emotional health and healthy habits, improvement of recreational and sports activities, as well as socializing with family and friends [7].

In addition to all the positive sides of cycling, one of the negative aspects refers to the safety of traffic participants, especially children, who have limited psychological and physical abilities [8-10]. The statistics of child casualties in European Union countries have shown that, in the last ten years, 8100 children were killed in traffic accidents (up to 15 years of age), out of which $13 \%$ were child cyclists [9]. On the territory of the Republic of Serbia, in the past ten years (2009-2018), there were a total of 12 child 
cyclist fatalities, up to 14 years of age, which is about $8 \%$ of total child fatalities [11]. That brings to the foreground the need to improve the readiness of children, as cyclists, to master the tasks and problems that arise in the complex traffic environment. All over the world there are cycling education programs that goal is general improvement of children safety in traffic, with special focus on elementary school children [12]. Research has revealed that cycling education programs for children between 8 to 10 years of age played an important role in promotion of cycling among children, adopting positive habits, social norms and favourable attitude towards traffic safety [13].

Previous studies were dealing with effects of children's cycling education programs and their influence on the change of knowledge, skills, attitudes, safety awareness and increasing cycling frequency and confidence, as well as decrease of share in the crashes or injures rate [13-19]. Cycling education programs in many countries in the world are implemented within curricular activities, as "The New Jersey Bike School program" from the USA [17], "Bike It" from the UK [20], "Miami BikeSafe" from the USA [16], "Safe Cycle" from Australia [14], "South Dunedin Cycling Project" from New Zealand [21].

Through analysis of the developed and applied cycling education programs and trainings, numerous differences in curriculum content, training duration, monitoring of knowledge after the training have been noticed [12], as well as in the population of children they target, in terms of age [13,18,22], gender, sociodemographic status, content of training (improvement of knowledge, skills, behaviour) [23], living areas and space where the training was conducted (traffic free environment or summer camp that included an on road component) [17,21]. Besides, there are obvious differences in the evaluation of training results (improvement was noticed or there was no change) $[18,19]$. Evaluation of most cycling safety education programs was related to their effects on skills and knowledge, and improvement was noticed in most cases [24]. Programs of knowledge improvement for children usually include knowledge with respect to understanding of cycling-related laws, traffic light signals, road signs, road rules, helmet use and fit, parts of the bike, visibility, while practical cycling skills programs refer to, for example, to following actions: straight-line riding, braking, shoulder check, bicycle safety checks etc.

Even though there are numerous studies of children cycling training, it is not well known which cycling training program for children is the best, for which population, under which conditions it is implemented [25]. Based on positive results and experience from previous researches, that refer to already existing cycling education programs that have been implemented in many school settings, it is obvious that in the countries that have not had training programs yet, there is a necessity for selection, development and integration of the best practices, programs and approaches in the school system through the curriculum. It is widely known that children do not normally approach adult performance levels until around 11-12 years of age [26]. Because of this, it is very important to develop and implement training programs for younger school children who do not have the knowledge and experience to deal with numerous tasks they encounter in traffic on a daily basis [12]. If we look at the existing cycling programs in different part of the world, they are mostly directed towards older school children, from grades 4 to 8 (10 to 14 years) and adolescents $[18,21,23,27]$. 
An initiation of a research and proposition of an education program and training for child cyclists is a special challenge in countries or regions where there is no organized approach to this very important issue. Serbia is one of four European countries where children learn about elementary traffic safety topics in primary school only [28]. According to the school curriculum, there are no individual subjects dedicated to traffic education; instead, there are only some topics (how to safely get to school, what are dangers in traffic, how to behave and what to do in these situations) within some subjects that the children learn. Consequences of such approach are children who have low level of traffic knowledge and skills to safely participate in a complex traffic environment. In addition, there are no benchmark studies and research on the territory of Serbia that deal with improvement of knowledge and skills of child cyclists. The foregoing facts clearly indicate the need for a pilot project implementation within primary schools and its promotion. It is especially important to point out and develop an approach for education of children in grades 1-4 of elementary schools in Serbia, who have not received formal education on cycling programs.

The main goal of the presented research is proposition of the concept of cycling safety education program and its implementation in the primary school curriculum where there is no such program, as well as evaluation of its effects on children's cycling knowledge and skills.

\section{Methods}

\section{Sampling}

A random sample of seventeen elementary schools in Serbia was selected to participate in the study. The school principals were sent a recruitment letter and afterwards contacted by phone. Nine schools agreed to participate of which five were allocated to the intervention group. In the process of evaluation of knowledge and skills of child cyclists the total number of students who participated in the research is 210 (115 students were from an intervention group, while 95 students were from a control group). Among lower elementary school grades, only students from the 4th grade were selected (between 9 to 10 years of age), since it is assumed that children of that age possess a skills and cognitive abilities to ride [29].

The presiding ethical committee sent Information Statement and Consent Form to all the parents of the children who were chosen to participate in the research. All the children who returned consent forms signed by parents as a confirmation that they are allowed to participate in the training, as well as in the knowledge and skills testing, were participants of the research.

The assumptions for analysis was that each student went through pre-training and post-training test of bicycle knowledge, as well as pre-training and post-training skills survey, and that the students from control group wasn't exposed to cycling training. A certain number of students from these schools did not meet the required assumptions for the following reasons: they did not attend the training or did not participate in the post-training test, also in the control group a certain number of students completed a test of bicycle knowledge, but did not participate to the training skills survey. The number of students who fulfilled the assigned requirements is 179 ( 96 students were from an intervention group, while 83 students were from a control group). Out of the total number of children in the intervention group, 40 (41.7\%) 
students were male, and 56 (58.3\%) female. In the control group, the sample consisted of 42 male students (50.6\%), and 41 female students (49.4). After the training, the knowledge and skills testing was applied to the same students within the control group ( $n=83$ students) and intervention group ( $n=96$ students).

\section{Measurements}

Evaluation of students' knowledge pre-training and post-training was done through a test at the first session and the final session. The adapted knowledge test [23] consisted of a series of 17 multiple choice questions with three or four options, in the form of a text, picture (situation), where they were supposed to circle the correct ones (Additional file 1). The duration of the test was 30 minutes. The test items referred to 7 learning models: age requirements (1 question), risky behaviour (1 question), bicycle parts and equipment (2 questions), cycling clothing gear (3 questions), road signs (3 questions), hand signals (3 questions) and understanding the road environment (4 questions).

Education process and skills testing for child cyclists were done at training ground which was designed for this research according to previous research $[30,31]$ (Fig 1). For the training and testing needs, the children were provided with youth sized bicycles and bicycle helmets. The students that had their own bicycle or helmet had to go through a testing and verification process, in order to ensure their safety and proper fit. Fifteen different aspects of child cyclists' behaviour were monitored in the process of practical evaluation of cycling skills on the school testing grounds before and after the implementation of the program, as it shown in Fig 1. So, for example, adjusting and checking the bicycle, as well as fitting and checking the helmet, left-turn signal, left turn, sudden braking skills, etc. were monitored and evaluated. Trained observers evaluated them on a five-degree scale, where 1 was the lowest mark, and 5 the highest (Additional file 2).

\section{Procedures}

The training program lasted for three months. Theoretical training was done by trained teachers with their students in school classrooms, while the practice was done on specially prepared training grounds within school yards. Taking into consideration the research goals and tasks for evaluation of knowledge and behaviour of children concerning traffic safety, in the schools that were the subject of the research, quasiexperimental research was applied (Fig 2). The reasons for application of this concept are: (1) partitions the students into control and intervention groups were done utilizing random selection method, (2) measurements were done in two time sessions (before and after the implementation of the program).

\section{Knowledge of child cyclists}

Theoretical activities were implemented in school classrooms once a week, for 45 minutes and consisted of 4 sections. Algorithm of cycling safety education program with the content of the units is given in Fig 3. The teachers discussed the given unit topic with the children, after which they performed didactic activities in the classroom. The teachers were provided with educational materials, presentations and 
outlines that they used in the training process. An example of a theoretical activity done by the teachers while improving cyclists' knowledge is shown in Table S1 for the unit that deals with the importance of helmet use for cyclists (Additional file 3).

\section{Child cyclists' skills}

The cycling skills program was also implemented by trained teachers on training grounds within schools. Sessions were done in one school period per week (45 minutes). The contents of the training program were based on practical exercises that children conducted on the training grounds, with the teacher's help. In order for the children to learn the planned skills more easily, the session topics also contained game elements, so the training process was more interesting and attractive for the children. The content of the cycling skills programs was based on similar exercises and material that was shown in earlier research [14]. Within the unit that deals with bicycle control and steering, a list of practical cycling skills that the teachers practiced with the children was given (Fig 3). An example of a practical activity that the teachers did during child cyclists' skills improvement is shown in Table S1, for the unit that deals with manoeuvring skills (Additional file 3 ).

\section{Results}

Data analysis was performed using IBM's SPSS Statistical Package (Version 22). Descriptive statistics were used to examine the basic features of the sample. Furthermore, data were analysed using repeated multivariate analysis of variance test.

\section{Analysis of child cyclists' knowledge}

Table 1 displays results of the two-way repeated multivariate analysis of variance (MANOVA) test. The test was carried out in order to examine the intervention effect on children's knowledge on cycling safety. The findings indicated that there was a statistically significant difference between the intervention and control group on children's cycling knowledge for the period of time $F(8,170)=2.99, p<0.01, \eta^{2}=0.12$. Univariate test was performed on each dependent variable, and revealed that intervention had a statistically significant multivariate effect on children's knowledge concerning age requirements for riding a bicycle on public roads $F(1,177)=7.37, p<0.01, \eta^{2}=0.04$, identification of risky cycling behaviour $F(1$, $177)=4.50, p<0.05, \eta^{2}=0.03$, road signs $F(1,177)=8.15, p<0.01, \eta^{2}=0.04$, and total knowledge score $F(1,177)=5.89, p<0.05, \eta^{2}=0.03$. In regards to knowledge of bicycle parts and equipment $F(1,177)=$ $0.03, p>0.05, \eta^{2}=0.00$, cycling clothing gear $F(1,177)=0.03, p>0.05, \eta^{2}=0.00$, using proper hand signals $F(1,177)=0.57, p>0.05, \eta^{2}=0.00$, and understanding of the road environment $F(1,177)=0.89, p>0.05$, $\eta^{2}=0.00$ statistically significant impacts for the time by condition interaction were not found.

Table 1 Effects of the intervention on children's cycling related knowledge 


\begin{tabular}{|c|c|c|c|c|}
\hline \multirow[t]{2}{*}{ Cycling knowledge } & \multirow[t]{2}{*}{ Group } & $\begin{array}{l}\text { Pre- } \\
\text { intervention }\end{array}$ & $\begin{array}{l}\text { Post } \\
\text { intervention }\end{array}$ & \multirow[t]{2}{*}{$\begin{array}{l}\mathrm{F}- \\
\text { value }\end{array}$} \\
\hline & & Mean (SD) & Mean (SD) & \\
\hline \multirow[t]{2}{*}{ Age requirements } & Control & $79.5(40.6)$ & $77.1(42.3)$ & \multirow[t]{2}{*}{$7.37 * \star$} \\
\hline & Intervention & $76.0(42.9)$ & $89.6(30.7)$ & \\
\hline \multirow[t]{2}{*}{ Risky behaviors } & Control & $100.0(0.0)$ & $96.4(18.8)$ & \multirow[t]{2}{*}{$4.50 *$} \\
\hline & Intervention & $89.6(30.7)$ & $94.8(22.3)$ & \\
\hline \multirow[t]{2}{*}{ Bicycle parts and equipment } & Control & $53.6(34.7)$ & $54.2(42.2)$ & \multirow[t]{2}{*}{0.03} \\
\hline & Intervention & $61.5(36.6)$ & $63.0(35.7)$ & \\
\hline \multirow[t]{2}{*}{ Cycling clothing gear } & Control & $72.7(27.7)$ & $72.7(31.7)$ & \multirow[t]{2}{*}{0.03} \\
\hline & Intervention & $80.2(24.5)$ & $80.9(26.4)$ & \\
\hline \multirow[t]{2}{*}{ Road signs } & Control & $68.0(22.1)$ & $67.7(24.0)$ & \multirow[t]{2}{*}{$8.15^{\star \star}$} \\
\hline & Intervention & $64.6(23.5)$ & $73.1(23.5)$ & \\
\hline \multirow[t]{2}{*}{ Hand signals } & Control & $83.1(37.7)$ & $85.5(35.4)$ & \multirow[t]{2}{*}{0.57} \\
\hline & Intervention & $82.3(38.4)$ & $80.2(40.1)$ & \\
\hline \multirow{2}{*}{$\begin{array}{l}\text { Understanding the road } \\
\text { environment }\end{array}$} & Control & $56.9(31.6)$ & $54.8(34.1)$ & \multirow[t]{2}{*}{0.89} \\
\hline & Intervention & $59.1(29.7)$ & $61.7(29.7)$ & \\
\hline \multirow[t]{2}{*}{ Total } & Control & $68.1(19.1)$ & $67.3(20.2)$ & \multirow[t]{2}{*}{$5.89 *$} \\
\hline & Intervention & $68.9(17.8)$ & $73.4(17.4)$ & \\
\hline
\end{tabular}

Note: ${ }^{*} \mathrm{p}<0.05 ;{ }^{* *} \mathrm{p}<0.01 ;{ }^{* \star *} \mathrm{p}<0.001$

\section{Child cyclists' cycling skills analysis}

The MANOVA was performed with the purpose of testing the effect of intervention on children's cycling skills (see Table 2). A statistically significant multivariate effect was obtained $F(15,163)=11.01, p<$ $0.001, \eta^{2}=50.30$, which demonstrates a significant difference between pre-intervention and postintervention period. The univariate tests indicated significant effect for fitting $F(1,177)=10.35, p<0.01$, $\eta^{2}=0.06$ and checking a helmet $F(1,177)=24.35, p<0.001, \eta^{2}=0.12$, adjusting a bicycle $F(1,177)=5.00$, $p<0.05, \eta^{2}=0.03$, starting the movement $F(1,177)=7.16, p<0.01, \eta^{2}=0.04$, cycling in a straight line $F(1$, $177)=6.77, p<0.05, \eta^{2}=0.04$, obeying the "stop" sign $F(1,177)=18.96, p<0.001, \eta^{2}=0.10$, riding through intersections $F(1,177)=34.02, p<0.001, \eta^{2}=0.16$, manoeuvring to avoid obstacles $F(1,177)=52.03, p<$ $0.001, \eta^{2}=0.23$, giving the signal for turning $F(1,177)=39.76, p<0.001, \eta^{2}=0.18$, turning left $F(1,177)$ $=98.15, p<0.001, \eta^{2}=0.36$, giving way to pedestrians $F(1,177)=15.57, p<0.001, \eta^{2}=0.08$, sudden braking 
and with control $F(1,177)=12.62, p<0.001, \eta^{2}=0.07$, manoeuvring around cones $F(1,177)=7.77, p<$ $0.01, \eta^{2}=0.04$, using a pedestrian crossing $F(1,177)=17.59, p<0.001, \eta^{2}=0.09$, and total cycling skills score $F(1,177)=127.20, p<0.001, \eta^{2}=0.42$. However, a non-significant interaction effect between control and intervention group was found in terms of checking the bicycle before riding $F(1,177)=2.21, p>0.05$, $\eta^{2}=0.01$.

Table 2 Effects of the intervention on children's cycling skills 


\begin{tabular}{|c|c|c|c|c|}
\hline \multirow[t]{2}{*}{ Cycling skills } & \multirow[t]{2}{*}{ Group } & Pre-intervention & Post intervention & \multirow[t]{2}{*}{$\mathrm{F}-$ value } \\
\hline & & Mean (SD) & Mean (SD) & \\
\hline \multirow[t]{2}{*}{ Fitting the helmet } & Control & $1,01(0.11)$ & $1,04(0.19)$ & \multirow[t]{2}{*}{$10.35^{\star \star}$} \\
\hline & Intervention & $1,04(0.20)$ & $1,46(1.11)$ & \\
\hline \multirow[t]{2}{*}{ Checking the helmet } & Control & $1,01(0.11)$ & $1,07(0.30)$ & \multirow[t]{2}{*}{$24.35^{\star \star \star}$} \\
\hline & Intervention & $1,04(0.20)$ & $1,71(1.03)$ & \\
\hline \multirow[t]{2}{*}{ Adjusting the bicycle } & Control & $1,02(0.22)$ & $1,06(0.24)$ & \multirow[t]{2}{*}{$5,00 *$} \\
\hline & Intervention & $1,03(0.17)$ & $1,24(0.59)$ & \\
\hline \multirow[t]{2}{*}{ Checking the bicycle } & Control & $1,05(0.44)$ & $1,04(0.19)$ & \multirow[t]{2}{*}{2.21} \\
\hline & Intervention & $1,04(0.41)$ & $1,19(0.74)$ & \\
\hline \multirow[t]{2}{*}{ Starting the movement } & Control & $4,17(1.46)$ & $4,07(1.31)$ & \multirow[t]{2}{*}{$7.16^{\star \star}$} \\
\hline & Intervention & $3,83(1.63)$ & $4,34(1.37)$ & \\
\hline \multirow[t]{2}{*}{ Cycling in a straight line } & Control & $4,52(1.15)$ & $4,53(1.05)$ & \multirow[t]{2}{*}{$6,77^{\star}$} \\
\hline & Intervention & $4,20(1.44)$ & $4,63(1.13)$ & \\
\hline \multirow[t]{2}{*}{ Obeying the 'stop' sign } & Control & $3,39(1.87)$ & $3,42(1.65)$ & \multirow[t]{2}{*}{$18,96 * \star *$} \\
\hline & Intervention & $3,29(1.89)$ & $4,45(1.38)$ & \\
\hline \multirow[t]{2}{*}{ Riding through intersections } & Control & $2,10(1.36)$ & $2,21(1.30)$ & \multirow[t]{2}{*}{$34,02 * \star *$} \\
\hline & Intervention & $2,27(1.50)$ & $3,74(1.42)$ & \\
\hline \multirow[t]{2}{*}{ Maneuvering to avoid obstacles } & Control & $1,60(0.62)$ & $1,68(0.61)$ & \multirow[t]{2}{*}{$52,03^{* * *}$} \\
\hline & Intervention & $1,46(0.58)$ & $2,70(1.21)$ & \\
\hline \multirow[t]{2}{*}{ Giving the signal for turning } & Control & $1,28(1.00)$ & $1,24(0.62)$ & \multirow[t]{2}{*}{$39,76 * \star \star$} \\
\hline & Intervention & $1,01(0.10)$ & $2,43(1.88)$ & \\
\hline \multirow[t]{2}{*}{ Turning left } & Control & $1,67(1.21)$ & $1,70(1.06)$ & \multirow[t]{2}{*}{$98,15^{\star \star \star}$} \\
\hline & Intervention & $1,45(1.02)$ & $3,52(1.30)$ & \\
\hline \multirow[t]{2}{*}{ Giving way to pedestrians } & Control & $3,92(1.54)$ & $3,88(1.43)$ & \multirow[t]{2}{*}{ 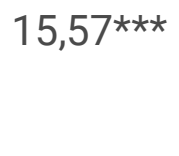 } \\
\hline & Intervention & $3,89(1.69)$ & $4,60(1.08)$ & \\
\hline \multirow[t]{2}{*}{ Sudden braking and with control } & Control & $3,78(1.65)$ & $3,73(1.46)$ & \multirow[t]{2}{*}{$12,62 * \star *$} \\
\hline & Intervention & $3,83(1.63)$ & $4,50(1.19)$ & \\
\hline Maneuvering around cones & Control & $3,64(1.48)$ & $3,72(1.46)$ & $7,77 * \star$ \\
\hline
\end{tabular}




\begin{tabular}{|lllll|} 
& Intervention & $3,48(1.51)$ & $4,09(1.47)$ & \\
Using a pedestrian crossing & Control & $1,48(0.92)$ & $1,51(0.68)$ & $17,59 \star \star *$ \\
\cline { 2 - 5 } & Intervention & $1,83(1.04)$ & $2,64(1.21)$ & \\
\hline Total & Control & $2,38(0.57)$ & $2,44(0.45)$ & $127,20 \star \star \star$ \\
& Intervention & $2,31(0.58)$ & $3,15(0.71)$ & \\
\hline
\end{tabular}

Note: ${ }^{\star} \mathrm{p}<0.05 ;{ }^{* \star} \mathrm{p}<0.01 ; * \star * \mathrm{p}<0.001$

\section{Discussion}

The purpose of this study are inception, implementation and evaluation the effects of the education program for school children cyclists in the sense of knowledge and improvement of practical skills for safe participation in traffic environment. A major strength of the present study is a carefully designed training program based on previous research and experience in this area and its application in school conditions while working with children who do not possess any aspect of formal cycling training.

The results of the presented study show that the cycling education program had an influence on the results in the sense of improving the knowledge of school children cyclists and that the acquired knowledge is the result of the implemented curriculum. This was in accordance with the previous studies which concluded that cycling education programs included in school settings resulted in improvement of knowledge on child safety $[16,17,24]$. That was confirmed by individual student answers to some questions and differences in pre- and post-training test scores. One of the most important indicators of improvement in test scores was noticed in questions that refer to who can ride a bicycle on public roads, as well as the questions about the importance of road signs and questions about risky behaviour in traffic. The students showed the lowest level of knowledge and improvement after the training through answers to questions that refer to the equipment and bicycle parts, as well as the understanding of the road environment. Knowledge improvement on understanding the road environment can be attributed to the lack of teachers' knowledge on the topic and their style of interpretation during the training. In regards to the obtained results, the future programs should pay special attention to the improvement of the curriculum and units that refer to this topic. The results also show that the children have good theoretical knowledge on certain safety topics, such as cycling clothing gear and hand signals, where most students showed admirable existing knowledge, so no significant knowledge improvement was noticed after the training. Similar results were confirmed in previous research, for example about good existing knowledge on the importance of helmet use [17]. There are several explanations for such results: the questions were clear and understandable for the students, it is possible that they heard about certain segments from their parents or someone from their environment, or they learned about some aspects previously at school.

A very positive finding of the present study is that the applied training program made significant improvements in children's basic cycling skills. This was in accordance with the previous studies that showed that training programs made significant improvements in primary school children's cycling skills 
$[12,18,19,32]$. The results of the presented study show that improvement is obvious in as many as fourteen out of the fifteen observed different cycling skills. That is justified by the fact that the children encountered the traffic safety skills training process for the first time and that, until then, they had not received any type of formal practical knowledge. A significant improvement was found in left turn, manoeuvring to avoid obstacles, giving the turn signal and riding through an intersection. Similar results were confirmed in previous research, where the biggest improvement was noticed in signalling [12]. Signalling by child cyclists is especially important, because in that way they send a message to other traffic participants on the change in their direction of movement. Such good results can be explained by the fact that these skills were well taught and practiced during practical sessions on school training grounds. Improvements were also found in checking the helmet. Out of all observed skills, there was no improvement only in checking a bicycle, while slight improvement was noticed in cycling in a straight line and starting the movement, which was also confirmed by the results of the research [12] that did not notice improvement before and after training for the named skills. Such result was expected, because the children probably learned these actions as primary skills as soon as they learned to ride a bicycle or while riding a bicycle with their parents.

The cycling training program in teachers' work with children showed that there are some results in improving children's knowledge and skills shortly after the training. This type of approach is especially important for countries, where there is no systematic and organized approach to solve the problem of child cyclists' education in grades one to four of elementary school.

\section{Limitations}

Besides the sound results of the study that show that the implemented training program for child cyclists was efficient in improving cycling knowledge and almost all skills, several limitations of the study should also be taken into account. As far as the sample is concerned, only nine of elementary schools (from seventeen that were chosen) were accepted participation in the research, but the number of children who participated in the research was satisfactory. This is the significant arguments that the awareness of the importance of cycling safety education program for school-age children is not at a satisfied level, so future research should be directed towards the promotion and implementation of it in many schools in the country. Also, during the testing on the training grounds, the children were trying to make conversation with the researchers who were evaluating the training course. In order to avoid that issue, it is advisable that, in future research, children might be recorded while they do the practical cycling test. Moreover, the small difference in the results of theoretical tests between the intervention and control groups may be attributed to the self-initiated activities of teachers in educating students about traffic behaviour.

Within this study, long-term effects of cycling training were not evaluated, which should be taken into consideration in future research.

\section{Conclusions}


Children, especially child cyclists, are the most vulnerable road users. Therefore, it is necessary to actively include them in programs that help raise awareness on the importance of traffic safety and acquiring skills needed to safely participate in traffic. It is especially important to point out that trainings can have an important influence when they are done with children under ten years old. The results of the training program evaluation showed that a cycling safety education program incorporated into school curriculum can result in an increase of children's knowledge relevant to cycling safety, and above all in improvement of child cyclists' skills for safe participation in traffic shortly after the training. The results undoubtedly confirm that the presented pilot study should serve as an initiative for starting, defining and implementation of an official training program for child cyclists in Serbia at the state or provincial level. Besides that, positive results of such approach and its application at the school level should also encourage the community and local government to get involved and support schools through construction of training grounds, promotion of classroom and training grounds competitions, to increase children's participation in cycling.

\section{Abbreviations}

MANOVA: multivariate analysis of variance; SPSS: Statistical Package for the Social Sciences; SD: standard deviation.

\section{Declarations}

\section{Ethics approval and consent to participate}

All procedures performed in this study were in accordance with the ethical standards and all participants completed informed written consent. We confirm that all methods were performed in accordance with the relevant guidelines and applicable regulations. Permission was obtained from Ministry of Education, Science and Technological Development of Republic of Serbia that the research can be conducted in schools. The age of the participants was between 9 to 10 years of age. Written informed consent was obtain from all the parents of the children who were chosen to participate in the research. The study was approved by review board which was formed by Public enterprise Roads of Serbia.

\section{Consent for publication}

Not applicable.

\section{Availability of data and materials}

The datasets used and/or analysed during the current study are available from the corresponding author on reasonable request.

\section{Competing interests}

The authors declare that they have no competing interests. 


\section{Funding}

This research was done with support by the Road rehabilitation and safety project (RRSP), "Road Safety awareness campaigns in schools in vicinity of project roads, RRSP/CS2-RSAC/2016-07", which has been assigned to Public enterprise Roads of Serbia. The funding bodies had no involvement in the study design, data collection, analysis and interpretation of data or the decision to submit for publication.

\section{Authors' contributions}

SB, DJ and BM are the main investigator and were involved in the study Design. SB, BM and MP were also involved in the data collection and analysis. SB, DS, DJ and BM contributed to the theory and design of the manuscript, and critically revised the final article. All authors read and approved the final manuscript.

\section{Authors' information}

${ }^{1}$ Department of Traffic Engineering, University of Novi Sad, Faculty of Technical Sciences, Department of Traffic Engineering, Novi Sad, Serbia; ${ }^{2}$ Department of Psychology, University of Priština - Kosovska Mitrovica, Faculty of Philosophy, Kosovska Mitrovica, Serbia, ${ }^{3}$ Faculty of Technical Sciences, University of Priština - Kosovska Mitrovica, Kosovska Mitrovica, Serbia

\section{Acknowledgements}

The authors want to thank all participating schools, teachers, research assistants and all children who participated in this project.

\section{References}

1. Mackett RL, Lucas L, Paskins J, Turbin J. The therapeutic value of children's everyday travel. Transportation Research Part A: Policy and Practice. 2005; doi: 1016/j.tra.2004.09.003

2. Oja P, Titze S, Bauman A, De Geus B, Krenn P, Reger-Nash B, Kohlberger T. Health benefits of cycling: a systematic review. Scandinavian journal of medicine \& science in sports. 2011; doi: 10.1111/j.1600-0838.2011.01299.x.

3. US Department of Health and Human Services. Physical activity guidelines advisory committee scientific report. 2018. https://health.gov/sites/default/files/201909/PAG_Advisory_Committee_Report.pdf. Accessed 10 Sept 2020.

4. World Health Organization. Global Recommendations on Physical Activity for Health. World Health Organization. 2010. https://www.who.int/dietphysicalactivity/publications/9789241599979/en/. Accessed 15 Jun 2020.

5. Kahlmeier S, Kelly P, Foster C, Götschi T, Cavill N, Dinsdale H, Woodcock J, Schweizer C, Rutter H, Lieb $\mathrm{C}$, Pekka $\mathrm{O}$. Health economic assessment tools (HEAT) for walking and for cycling: methodology and user guide: economic assessment of transport infrastructure and policies: 2014 update. World Health 
Organization. 2014. https://www.euro.who.int/en/publications/abstracts/health-economicassessment-tools-heat-for-walking-and-for-cycling.-methodology-and-user-guide.-economicassessment-of-transport-infrastructure-and-policies.-2014-update. Accessed 10 Sept 2020.

6. Sælensminde K. Cost-benefit analyses of walking and cycling track networks taking into account insecurity, health effects and external costs of motorized traffic. Transportation Research Part A: Policy and Practice. 2004; doi: 1016/j.tra.2004.04.003.

7. Lustenberger T, Inaba K, Talving P, Barmparas G, Schnüriger B, Green D, Plurad D, Demetriades D. Bicyclists injured by automobiles: relationship of age to injury type and severity-a national trauma databank analysis. Journal of Trauma and Acute Care Surgery. 2010; doi:

10.1097/TA.0b013e3181d0f68b.

8. Children in road traffic: Deliverable 4.8c of the EC FP7, project DaCoTA.DaCoTA. 2012. http://www.dacota-project.eu/Deliverables/Webtexts/Child\%20Traffic\%20Safety.pdf. Accessed 5 Aug 2020.

9. European Transport Safety Council. Reducing child deaths on European roads (Pin Flesh Report 34). European Transport Safety Council.2018. https://etsc.eu/reducing-child-deaths-on-european-roadspin-flash-34/. Accessed 15 Sept 2020.

10. National Highway Traffic Safety Administration (NHTSA). Traffic Safety Facts: 2017 Data. Bicyclists and Other Cyclists. U.S. Department of Transportation.

2019.https://crashstats.nhtsa.dot.gov/Api/Public/ViewPublication/812765. Accessed 10 Aug 2020.

11. Road Traffic Safety Agency. Statistical report on the state of road safety in the Republic of Serbia for the year 2017. Road Traffic Safety Agency. 2019.

https://www.abs.gov.rs/admin/upload/documents/20181016102526-

statistical_report_2017_english.pdf. Accessed 15 July 2020.

12. Ducheyne F, De Bourdeaudhuij I, Lenoir M, Cardon G. Effects of a cycle training course on children's cycling skills and levels of cycling to school. Accident Analysis \& Prevention. 2014; doi:1016/j.aap.2014.01.023.

13. Richmond SA, Zhang YJ, Stover A, Howard A, Macarthur C. Prevention of bicycle-related injuries in children and youth: a systematic review of bicycle skills training interventions. Injury prevention. 2014; doi: 1136/injuryprev-2013-040933.

14. Hatfield J, Dozza M, Patton DA, Maharaj P, Boufous S, Eveston T. On the use of naturalistic methods to examine safety-relevant behaviours amongst children and evaluate a cycling education program. Accident Analysis \& Prevention. 2017; doi: 1016/j.aap.2017.08.025.

15. Hatfield J. A review of evaluations of bicycle safety education as a countermeasure for child cyclist injury. Journal of the Australasian College of Road Safety. 2012; 23(2), 20.

16. Hooshmand J, Hotz G, Neilson V, Chandler L. BikeSafe: evaluating a bicycle safety program for middle school aged children. Accident Analysis \& Prevention. 2014; doi: 1016/j.aap.2014.01.011.

17. Lachapelle U, Noland RB, Von Hagen LA. Teaching children about bicycle safety: an evaluation of the New Jersey Bike School program. Accident Analysis \& Prevention. 2013; doi: 
1016/j.aap.2012.09.015.

18. Sersli S, Scott N, Winters M. Effectiveness of a bicycle skills training intervention on increasing bicycling and confidence: a longitudinal quasi-experimental study. Journal of Transport \& Health. 2019; doi: 1016/j.jth.2019.100577.

19. SersliSersli S, DeVries D, Gislason M, Scott N, Winters M. Changes in bicycling frequency in children and adults after bicycle skills training: A scoping review. Transportation research part A: policy and practice. 2019; doi: 1016/j.tra.2018.07.012.

20. Bike it plus London. Sustrans. 2019. https://www.sustrans.org.uk/ourblog/projects/2019/london/bike-it-plus-london. Accessed 15 Sept 2020.

21. Mandic S, Flaherty C, Pocock T, Kek CC, McArthur S, Ergler C, Chillón P, Bengoechea EG. Effects of cycle skills training on children's cycling-related knowledge, confidence and behaviours. Journal of Transport \& Health. 2018; doi: 1016/j.jth.2017.12.010.

22. Hamann CJ, Conrad A. Inventory of child bicycle education programs reveals need for age, development, and skill-level considerations. Traffic injury prevention. 2019; doi: 1080/15389588.2019.1665651

23. Mandic S, Flaherty C, Ergler C, Kek CC, Pocock T, Lawrie D, Chillón P, Bengoechea EG. Effects of cycle skills training on cycling-related knowledge, confidence and behaviour in adolescent girls. Journal of Transport \& Health. 2018; doi: 1016/j.jth.2018.01.015.

24. Hatfield J, Boufous S, Eveston T. An evaluation of the effects of an innovative school-based cycling education program on safety and participation. Accident Analysis \& Prevention. 2019; doi: 1016/j.aap.2019.02.021.

25. Goodman A, van Sluijs EM, Ogilvie D. Cycle training for children: Which schools offer it and who takes part? Journal of Transport \& Health. 2015; doi: 1016/j.jth.2015.07.002

26. Gillham B, Thompson J. Child Safety: Problem and Prevention from Pre-School to Adolescence: A Handbook for Professionals. Routledge; 2005.

27. Mandic S, Flaherty C, Pocock T, Kek CC, Chillón P, Ergler C, Bengoechea EG. Parental perceptions of cycle skills training for adolescents. Journal of Transport \& Health. 2017; doi: 1016/j.jth.2017.03.009.

28. Mütze F, De Dobbeleer W. The status of traffic safety and mobility education in Europe. European Transport Safety Council. 2019. https://etsc.eu/the-status-of-traffic-safety-and-mobility-education-ineurope/. Accessed 14 Jun 2020.

29. Briem V, Radeborg K, Salo I, Bengtsson H. Developmental aspects of children's behavior and safety while cycling. Journal of pediatric psychology. 2004; doi:10.1093/jpepsy/jsh040.

30. Ducheyne F, De Bourdeaudhuij I, Lenoir M, Spittaels H, Cardon G. Children's cycling skills: Development of a test and determination of individual and environmental correlates. Accident Analysis \& Prevention. 2013; doi: 1016/j.aap.2012.06.021

31. Zeuwts L, Vansteenkiste P, Cardon G, Lenoir M. Development of cycling skills in 7-to 12-year-old children. Traffic injury prevention. 2016; doi: 1080/15389588.2016.1143553. 
32. Van Schagen IN, Brookhuis KA. Training young cyclists to cope with dynamic traffic situations. Accident Analysis \& Prevention. 1994; doi: 1016/0001-4575(94)90092-2.

\section{Figures}

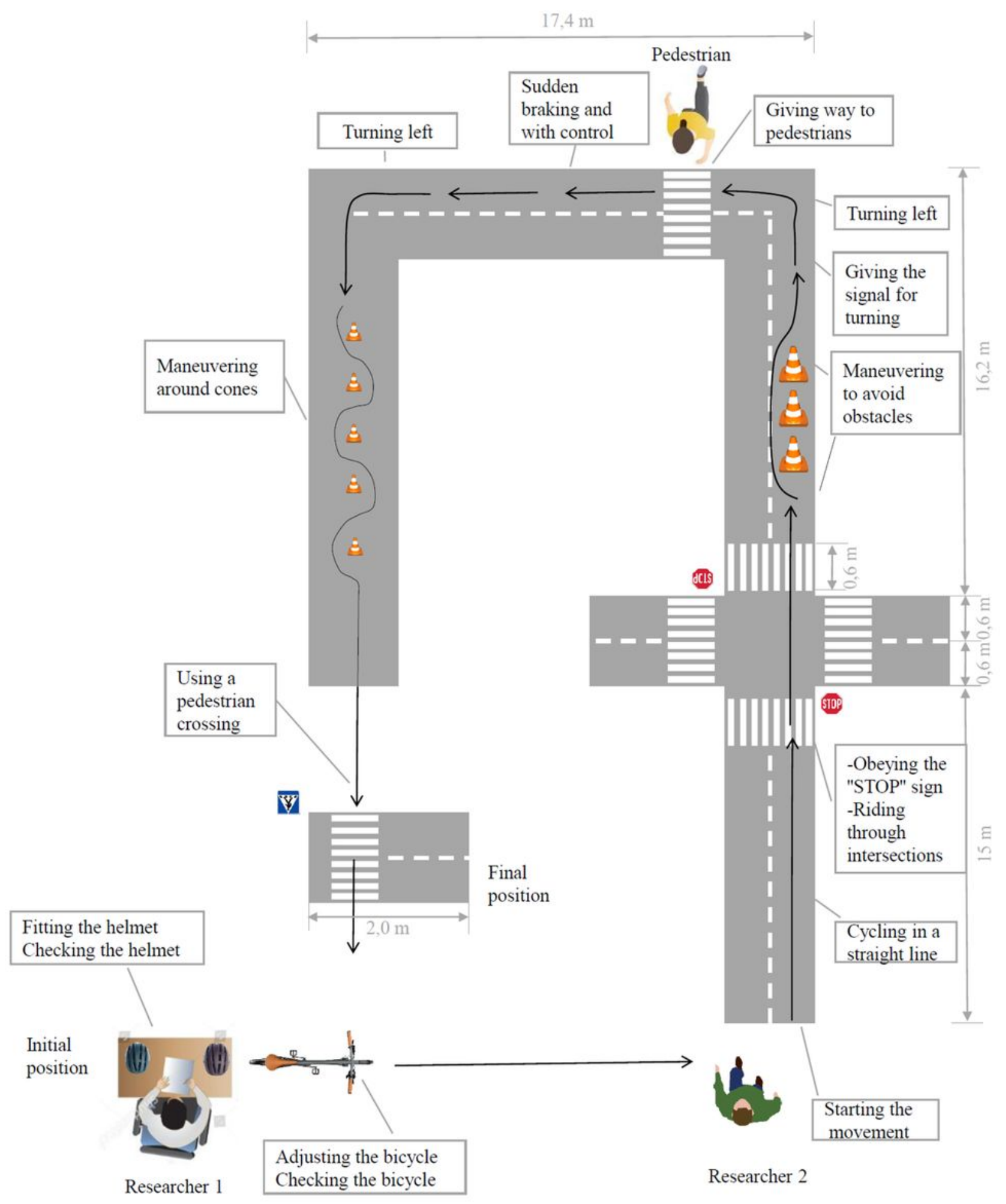

Figure 1 


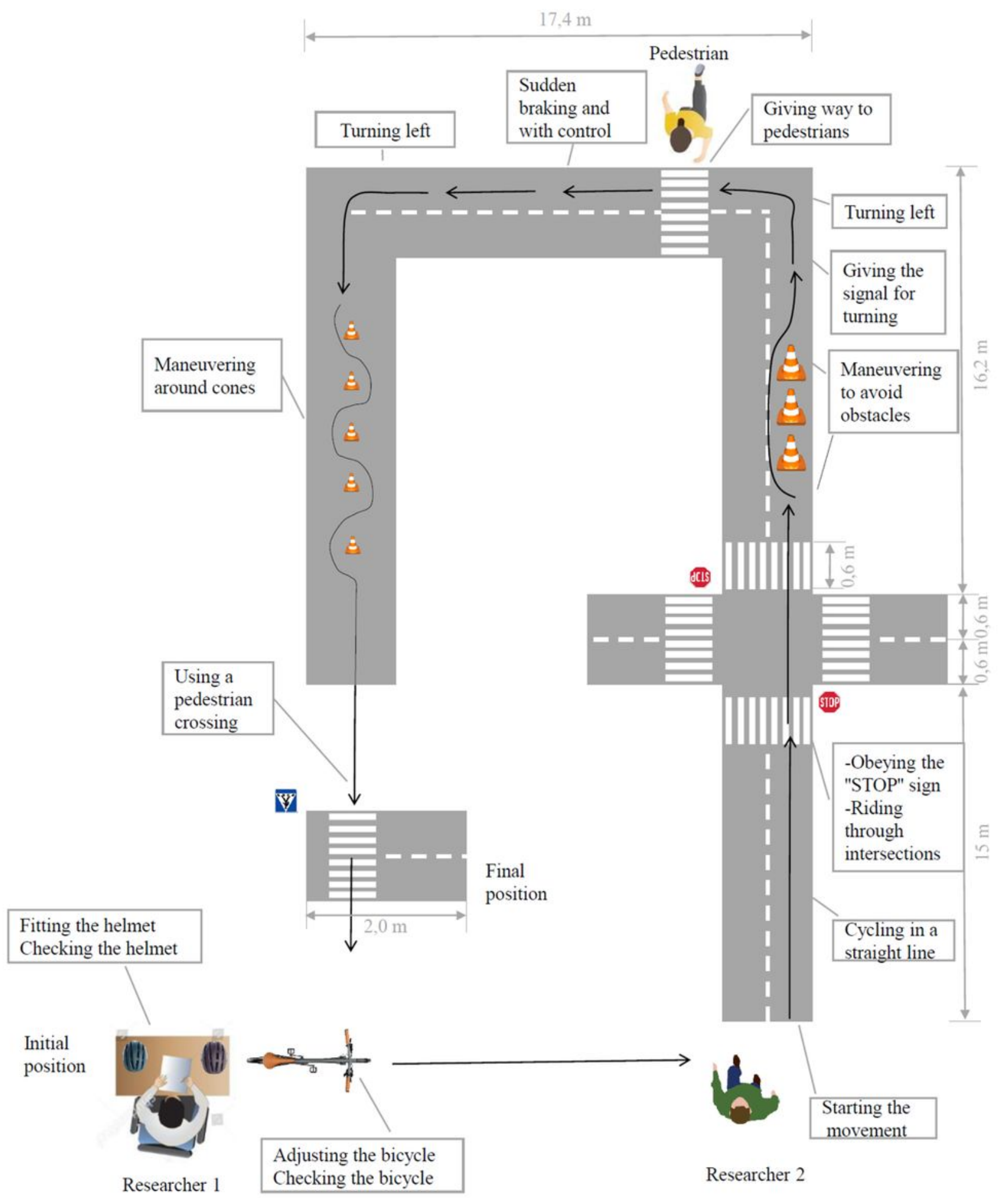

Figure 1

Quasi-experimental research concept 


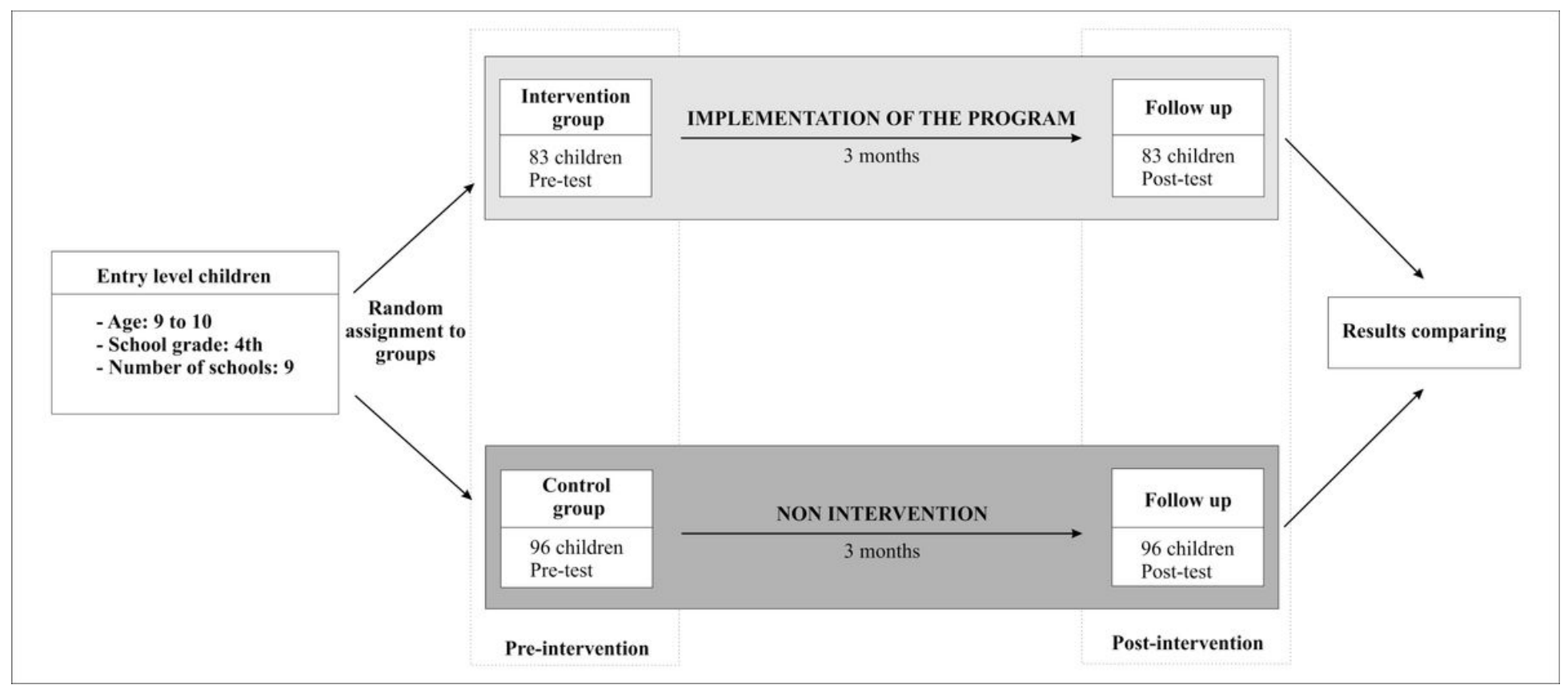

Figure 2

Quasi-experimental research concept

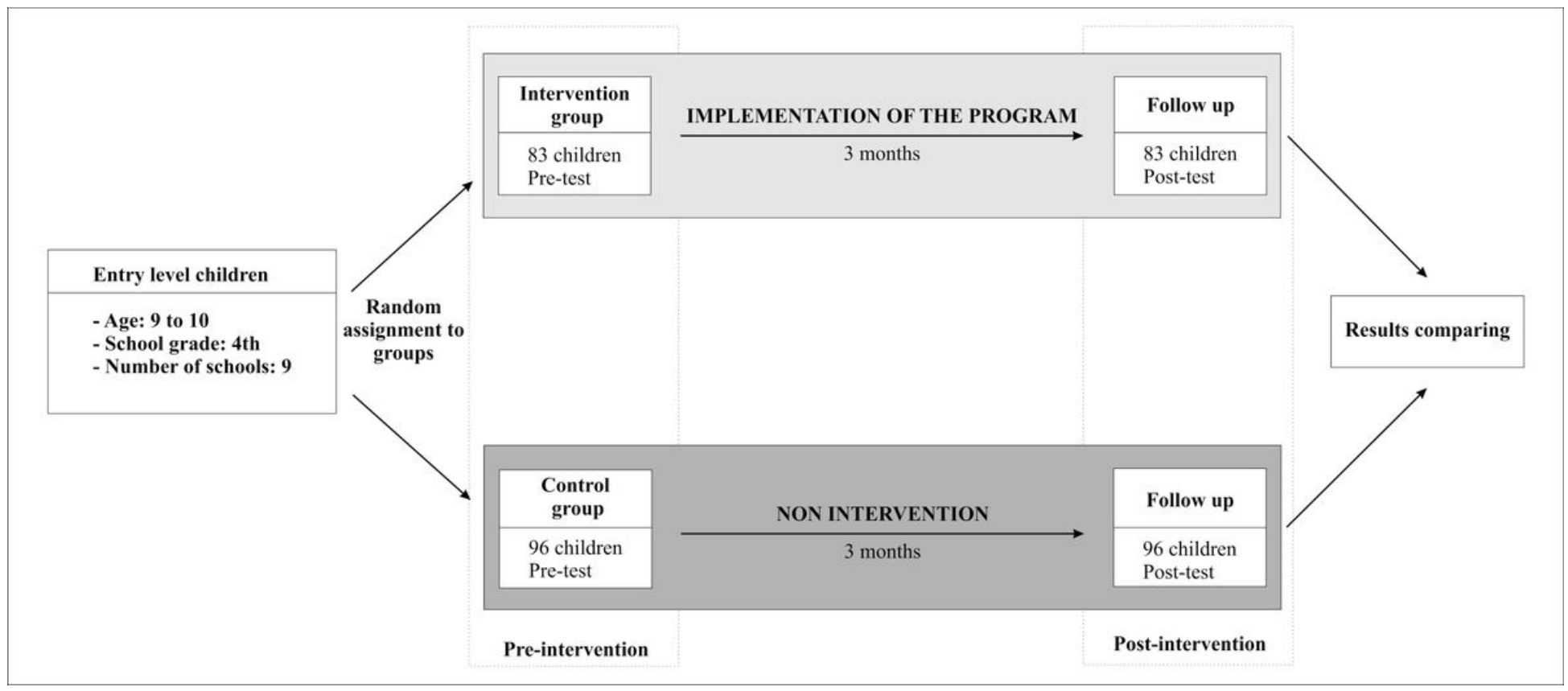

Figure 2

Quasi-experimental research concept 


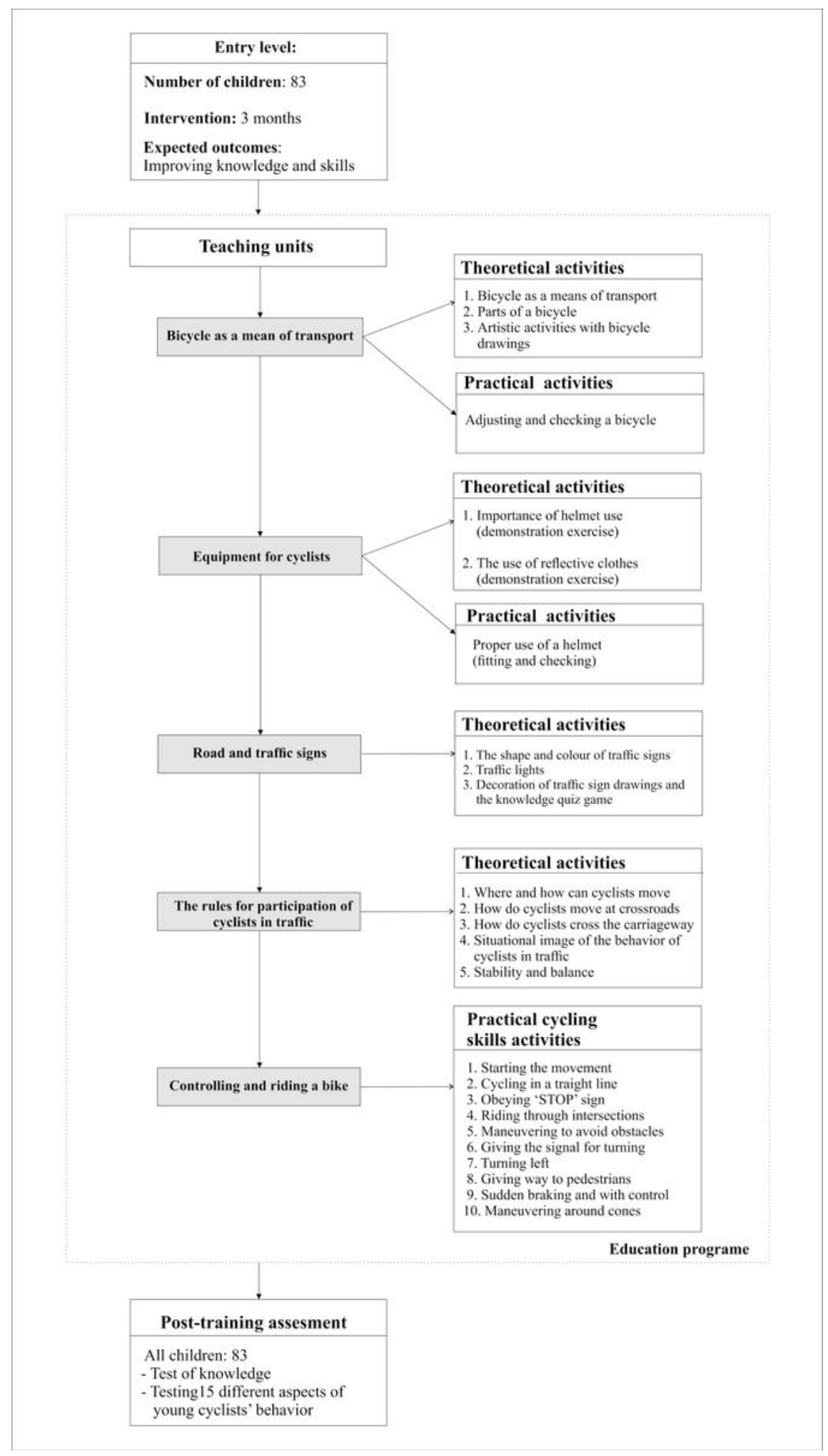

\section{Figure 3}

Implementation algorithm for cycling safety education program - lesson progression 


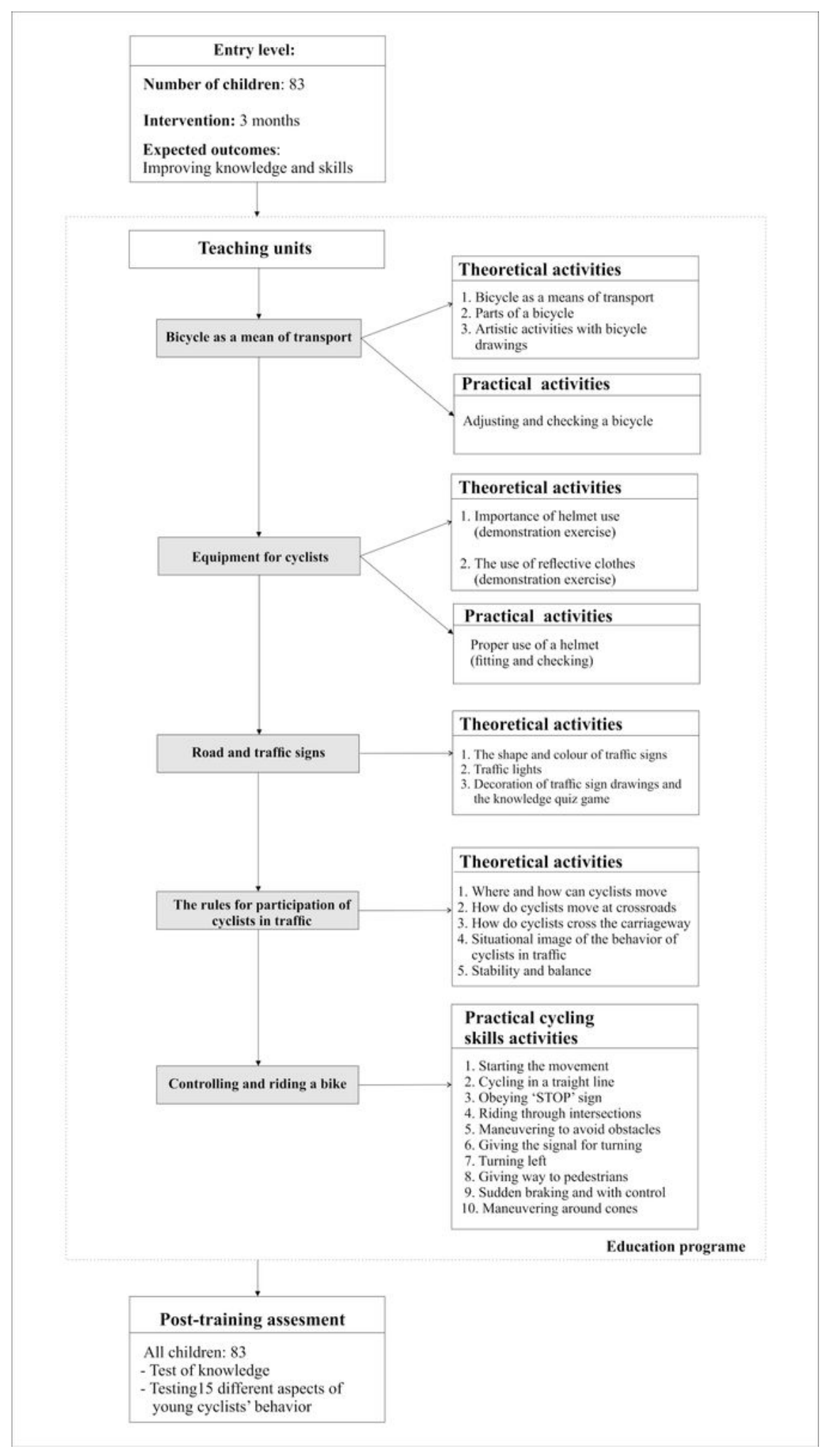

\section{Figure 3}

Implementation algorithm for cycling safety education program - lesson progression

\section{Supplementary Files}

This is a list of supplementary files associated with this preprint. Click to download. 
- Additionalfile2...Evaluationsheet.docx

- Additionalfile2...Evaluationsheet.docx

- Additionalfile1...Knowledgetest.docx

- Additionalfile1...Knowledgetest.docx

- Additionalfile3...Anexampleofatheoreticalactivity.docx

- Additionalfile3...Anexampleofatheoreticalactivity.docx 